\title{
Marcuses Asche. Ein Essay
}

\section{Helmut Dubiel}

1. Prolog: Die hier erzählten, wenige Tage umfassenden Ereignisse Ende der 70er Jahre im vergangenen Jahrhundert, als der Philosoph Herbert Marcuse in Deutschland starb und später dann zu Beginn des 21. Jahrhunderts, als seine Asche in Berlin zu Grabe getragen wurde, erscheinen in der historischen Distanz wie Splitter eines zerborstenen Spiegels, die das Bild der Vergangenheit nur verschwommen und bruchstückhaft reflektieren.

Obwohl ich, der Verfasser, zum großen Teil Zeuge der geschilderten Ereignisse war, ist die vorliegende Erzählung kein wirklichkeitsgetreuer Bericht. Die mir selbst gestellte Aufgabe, die Splitter des Spiegels wieder so zusammen zu fügen, dass ein kohärentes Bild daraus entsteht, erforderte eher poetische Kompetenzen denn die eines Chronisten. ${ }^{1}$

Mein Bericht ist keine Biographie über Marcuses Leben und keine Monographie über Aspekte seiner Philosophie. Mehr als von seinem Leben wird von seinem Sterben, seinem Tod und von seiner Beerdigung die Rede sein sowie von den fast 25 Jahren, die dazwischen lagen. Erzählt wird die Geschichte, wie die Urne mit der Asche des verstorbenen Philosophen, die für fast ein Vierteljahrhundert als verschollen galt, unversehens im Lagerraum einer Synagoge in New Haven, Connecticut, auftauchte, als ein niederländischer Student nach einem Ort suchte, wo man des Toten gedenken konnte.

Herbert Marcuse starb am 29. Juli 1979 in Starnberg. Der Schlaganfall, der ihn das Leben kostete, kam nicht völlig überraschend. Auf fast jeder Station seiner langen EuropaReise hatte er einen Arzt aufsuchen müssen. In München, der letzten Etappe vor seinem Tod in Starnberg, lag er gar mehrere Tage in der Universitätsklinik. Seine Verwandten

(C) VS-Verlag 2010

Autorenangabe: Helmut Dubiel war von 1989-1997 Forschungsdirektor am Institut für Sozialforschung der Universität Frankfurt a.M. Von 1999 bis 2003 „Max Weber Professur“ an der NEW YORK University seit Oktober 2009 Professor emeritus an der Justus Liebig Universität Giessen.

Prof. em. H. Dubiel $(\bowtie)$

Institut für Soziologie der Universität Gießen, Gießen, Deutschland

E-Mail: Helmut.Dubiel@sowi.uni-giessen.de

1 Helmut Dubiel ist Herausgeber der Werke von Leo Löwenthal. Sein Buch mit dem Titel „Tief im Hirn“ ist 2006 im Antje Kunstmann Verlag, München, erschienen. 
und Freunde waren angesichts seines Alters und seiner ohnehin fragilen Gesundheit sehr besorgt. Sie hätten es am liebsten gehabt, wenn er die Reise einfach abgebrochen hätte. Nur scheiterte dieses Ansinnen von vorneherein an seiner so stoischen wie störrischen Weigerung, sein Leben nur noch unter der Prämisse der Schonung zu leben. Rainer Werner Fassbinder zitierend sagte er oft, sich schonen könne er noch ausgiebig, wenn er tot sei. Er meinte, wenn er schon sterben müsse, sei es am besten auf einer Vortragsreise, vielleicht gar in einem Luxushotel am Starnberger See oder im Grand-Hotel in Pontresina in der Schweiz.

Als Folge des Schlaganfalls litt Marcuse unter linksseitigen Bewegungseinschränkungen. Aber er war bei Bewusstsein, konnte klar sprechen und organisiert denken. In den ersten Tagen wollten die Ärzte nicht ausschließen, dass er mit kleineren ,schlaganfalltypischen Defiziten“ - wie sie sich ausdrückten - überleben werde. Doch nach einer Woche im Krankenhaus verschlechterte sich sein Zustand dramatisch. Es war klar, dass er bald sterben würde.

2. Besuche von und bei Marcuses: In dem Jahr, in dem Marcuse in Starnberg starb, lebte ich in einem Holzhaus nahe dem Starnberger See, das den Eltern meiner Freundin Angelika gehörte. Dass Starnberg zum Schauplatz der hier erzählten Geschichte wurde, ist nicht völlig zufällig. Jürgen Habermas hatte Herbert Marcuse, wie schon im Jahr zuvor, zu einem Colloquium am Starnberger Max-Planck-Institut zur Erforschung der Lebensbedingungen der wissenschaftlich-technischen Welt eingeladen. Ich bereitete seinerzeit die Edition der Schriften von Leo Löwenthal vor. Löwenthal war wie Marcuse ein betagter deutsch-jüdischer Gelehrter, der wie Marcuse der Frankfurter Schule zugerechnet wurde. Beide waren seit ihrer Flucht vor den Nazis enge Freunde und besuchten sich regelmäßig. Schon bevor Marcuse auf seiner Europareise im Juli 1979 erkrankte, hatte Löwenthal mich diskret auf die Möglichkeit aufmerksam gemacht, dass die Familie unsere Unterstützung in Starnberg brauchen könnte.

Für Angelika war es selbstverständlich, dass sie dem Wunsch der Mitglieder der Marcuse-Familie entsprechen würde, bei ihr zu wohnen. Diese Großfamilie umfasste zunächst Marcuses (dritte) Frau Ricky, sodann seinen Sohn Peter, dessen Sohn Harold (also den Enkel Herbert Marcuses) sowie seine beiden Stiefsöhne Thomas und Michael Neumann. Es war kaum abzusehen, wie lange der prekäre Zustand zwischen Leben und Tod dauern würde. Klar war indes, dass es der Familie finanziell nicht zuzumuten war, in einem teuren Luxushotel für ungewisse Zeit zu logieren. Entsprechend gern zog die „Marcuse-Familie“ in das Holzhaus ein.

Zwei Jahre zuvor hatten Angelika und ich Herbert Marcuse bei einem Dinner, das Leo Löwenthal in Berkeley ausrichtete, kennen gelernt. Wir waren anschließend auf seine Einladung hin mit dem Auto von San Francisco nach La Jolla gefahren, wo Marcuse wohnte. Es ist ein Ort zwischen San Diego und der mexikanischen Grenze. Erschöpft von der langen Fahrt auf dem Highway Number one, der sich von Oregon bis nach Mexiko schlängelt, geblendet von einem Sonnenlicht, dem keine europäische Sonnenbrille gewachsen war, betraten wir Marcuses schattiges Büro. Hinter einem wohl aufgeräumten Schreibtisch erhob sich eine von schlohweißen Haaren gekrönte Gestalt. Er war groß und schlank, überragt von hohen Bücherregalen, die die gesamte Wand des kleinen Büros bedeckten. Trotz seiner vom Alter gebeugten Gestalt bewegte er sich mit einer gewissen 
schlaksigen Eleganz. Noch ehe wir etwas sagen konnten, konfrontierte er uns mit der Frage, die wir erst nach einer Wiederholung verstanden. „Wie geht es Sartre?“ Sartre lag damals im Sterben. Wir hatten Tage zuvor zwar eine Notiz über Sartres Sterben in der New York Times gelesen, waren aber über seine gegenwärtige Befindlichkeit nicht informiert.

Es gab weitere Fragen, die wir nicht sofort zu seiner Zufriedenheit beantworten konnten; zum Beispiel nach der akademischen Repräsentanz der Psychoanalyse an den deutschen Universitäten; oder nach dem Verhältnis von Habermas', Theorie des kommunikativen Handelns“ zur klassischen kritischen Theorie. Ich war von der Unmittelbarkeit von Marcuses Interesse an den führenden Figuren des europäischen Geisteslebens beeindruckt und leicht eingeschüchtert.

Marcuses Leben fügt sich nicht in das Schema einer akademischen Biographie. Gewiss, er war ein Intellektueller und ein Gelehrter von hohem Rang, jedoch mit einer gänzlich unakademischen Physiognomie. Die Abwesenheit von Dünkel und Eitelkeit, seine ihm ins Gesicht geschriebene Unbestechlichkeit, seine Wachheit und Offenheit - all diese Merkmale sind bei einem durchschnittlichen akademischen Charakter eher die Ausnahme als die Regel. Aber ebenso wenig lässt sich Marcuses Lebensgeschichte auf den Wechselrahmen einer politischen Biographie spannen. Seine frühen episodischen Aktivitäten beim Arbeiter- und Soldatenrat in den revolutionären Wirren der Zeit nach dem Ersten Weltkrieg, die Erfahrung des Untergangs der Weimarer Republik, die Erfahrung als Jude und Marxist aus Deutschland vertrieben zu werden, dessen Kultur er Zeit seines Lebens tief verbunden blieb und schließlich die Rolle als weltweit beachteter Theoretiker der Studentenbewegung waren die wichtigsten Bestimmungskräfte seines Lebens.

3. Im Supermarkt: Obwohl wir uns kaum kannten, lud uns Marcuse spontan zu einem späten lunch zu sich nach Hause in La Jolla ein. Zuvor machten wir Besorgungen in einem „Safeway“-Supermarkt. Er machte einen zerstreuten Eindruck, als er den Einkaufskorb mit etwas Obst füllte, mit einer Dose mexikanischer Bohnen, Fertigreis, drei Steaks sowie eine Flasche Ballantines-Whisky. Angelika und ich waren bis dahin noch nicht oft in den USA gewesen; und wir hatten uns an die Warenpracht und monströse Größe der Supermärkte und ihres Warenangebots noch nicht gewöhnt. Pampelmusen in der Größe von Kindsköpfen, Milch nicht literweise, sondern in Gallonen, d. i. die vierfache Menge, alle Waren wie Butter, Kaffee und Brot in unzähligen Sorten, Preisvarianten und Mengenkontingenten ...

Ich fragte Marcuse, ob es diese Konsumpracht gewesen sei, die ihn zu der Unterscheidung von „wahren“ und „falschen“ Bedürfnissen inspiriert habe. Er schwieg, bis wir wieder im Auto sassen. Ehe er den Motor startete, begann er zu sprechen. Er sagte, die Formulierung eines Unterschieds zwischen ,wahren“ und „falschen Bedürfnissen“ würde er heute in seinen Vorträgen und Schriften nicht mehr verwenden, weil sie ihm viel zu schwach erscheine. Im modernen Kapitalismus habe die Differenziertheit des Konsumangebots ein absurdes Ausmaß erreicht, und es sei ein komplettes Missverständnis, dass dieser Differenziertheit im Angebot eine Qualitätssteigerung entspräche. Die glitzernde Warenfülle in den shopping malls sei kein Anzeichen für gesellschaftlichen Reichtum, eher für kulturelles Elend. Bei Automobilen oder Kühlschränken habe es seit Jahrzehnenten keine nennenswerte technische Innovation mehr gegeben, sehr wohl aber viele 
kosmetische Veränderungen in der äusseren Form und ständig steigende Preise in Folge der hohen Werbeetats. In einer utopischen Gesellschaft, wie sie ihm vorschwebe, gäbe es nur wenige Warentypen. Sie seien billig, praktisch und robust.

4. Zu Hause: Wir waren sehr neugierig auf Marcuses Haus. Wir hatten uns vorgestellt, dass Marcuse dank der weltweiten Verbreitung seiner Bücher ein wohlhabender Mann sein müsse. Auf der anderen Seite war demonstrativer Luxus seine Sache nicht. Nun, das Haus fügte sich auf wundersame Weise unseren widersprüchlichen Erwartungen. Von außen wirkte es bescheiden, mit einem kleinen, gepflegten Gärtchen zur Strasse hin und Ziergittern vor den Fenstern zum Schutz vor Einbrechern. Es war ein Allerweltshaus in einer mittelständisch-kleinbürgerlichen Nachbarschaft. Nichts deutete auf die Prominenz seines Bewohners hin. Aber das Interieur des Hauses gefiel uns sofort. Von innen wirkte es viel größer als von außen. Trotz der üppigen Möblierung, die ganz auf die Bequemlichkeit eines greisen Gelehrten zugeschnitten war, war das Haus nicht vollgestopft. Allgegenwärtig lagerten säuberlich Kante auf Kante geschichtete Bücherstapel. Kein Regal war groß genug, um die Stapel zu fassen.

Sie waren schon deshalb nicht groß genug, weil Platz ausgespart blieb für allerlei Zierat, vor allem für viele kleine Nilpferde in verschiedenen Formen, Farben und Aggregatzuständen. Diese Liebe für Nilpferde teilte Marcuse mit Leo Löwenthal. Bei jedem seiner Besuche in der Bay-Region besuchten die beiden alten Männer den Zoo, ebenso wie Löwenthal es tat, wenn er seinen Freund in San Diego traf.

Auffallend war die Selbstverständlichkeit, mit der Marcuse uns, seine Gäste, in die Vorbereitung des nachmittäglichen lunch einbezog. Daran wurde uns deutlich, in welchem Ausmaß er den Umgang mit jungen Leuten gewohnt war. Auf sein Geheiß hin legte ich drei Steaks in die Pfanne, öffnete die Konservendose mit den „frijoles“ und wärmte sie in der Mikrowelle auf. Schließlich kochte ich Reis. Währendessen hatte Angelika mit Marcuse den Tisch gedeckt. Bevor wir aßen, hatte der Gastgeber die Flasche Ballantines geöffnet und zwei Wassergläser mit Whisky halb gefüllt. Nachdem ich das Glas geleert hatte, spürte ich wie die Spannung sich löste, die mich seit unserer Ankunft im Griff gehabt hatte.

Ich erinnerte Marcuse daran, dass er uns noch eine Definition schulde für die Problematik, die er zuvor mit der Unterscheidung von ,wahren“ und „falschen“ Bedürfnissen umschrieben habe. Das habe er keineswegs vergessen, entgegnete er; seit wir den ,safeway“-Supermarkt verlassen hätten, ginge er mit einem Gedanken schwanger, vor dessen Artikulation er noch zurückschrecke; doch mit dem Ballantines als Geburtshelfer werde es schon gehen. Und dann sagte er fast beiläufig: Der Supermarkt sei eine dialektische Einheit von KZ und Paradies. Ein KZ sei er, da er die totalitäre Unterwerfung des Menschen unter die Zwänge des Marktes exemplarisch verkörpere; ein Paradies, weil er die unbegrenzte Warenfülle vorwegnehme, die Marx erst für die „reife“ Entwicklungsphase des Kommunismus verheißen habe.

Später berichtete ich Freunden von einem heimlich aufkeimenden Gefühl jähen Zorns. Paradoxerweise hat der Alkohol mir geholfen, meine Ruhe zu bewahren. Ich stammelte ein wenig, um meine Fassung wieder zu finden, denn ich fand den Vergleich schlicht empörend und kitschig. Beide Seiten von Marcuses Argument machten mich aufsässig; sowohl die Gleichsetzung des süd-kalifornischen Supermarktes mit Marx’ Konzeption 
des reifen Kommunismus als auch die Bagatellisierung des KZ durch den Vergleich mit „Safeway“ waren völlig daneben. Angelika trat mir unterm Tisch auf den Fuß und schaute mich beschwörend an. Sie kannte mich gut genug und wusste, wie sehr mich diese sonderbare Konsumkritik und dann noch die Anspielung aufs KZ irritierte. Doch ich konnte meinen Ärger nicht ganz herunterschlucken und erzählte - scheinbar ohne Zusammenhang - eine Geschichte von Andrzej Szcypiorski. In dieser Geschichte versucht ein polnischer Lehrer und Kommunist den Schülern die kommunistische Utopie mit dem Argument schmackhaft zu machen, dass es dann Johannesbeerpudding für alle gebe. Ein Schüler wendet ein, dass er Johannesbeerpudding gar nicht mag. „Nach der Revolution wirst du ihn mögen“, wird ihm beschieden. Marcuse schaute mich an, in einer eigentümlichen Mischung aus Erstaunen und Spott. „Gut gebrüllt, Löwe, aber leider etwas daneben gesprungen“", bemerkte er trocken. Johannesbeerpudding möge er übrigens auch nicht, auch nicht nach einer Revolution.

Ich zog es nun vor, assistiert von einem weiteren Glas Ballantines, in brütendes Schweigen zu fallen und Angelika die Konversation zu überlassen. Angelika erzählte beiläufig von einer Edward-Hopper-Ausstellung, die sie im MOMA in New York gesehen hatte. Marcuse zeigte sich interessiert und informiert. Sein Überblick nicht nur über sein Fach, sondern auch über Malerei, Filme und Romane war umso imposanter, als er sich ebenso selbstverständlich in der deutschen, der französischen und der angelsächsischen Kultur bewegte. Als er dann noch, vielleicht um der jungen Frau zu imponieren, Passagen aus der Ilias rezitierte, stand mir und Angelika für kurze Zeit der ungeheure Verlust vor Augen, den die deutsche Kultur durch die Vertreibung und Vernichtung jüdischer Gelehrter sich selbst zugefügt hatte. Denn es war nicht nur der Exodus einer Person, sondern das Ende eines intellektuellen Universums, das sich in ihm und seinen geistigen Weggefährten verkörperte. Ich nahm mir fest vor, mit ihm darüber zu reden. Doch bevor ich eine Form fand, Marcuse selbst danach zu befragen, drehte sich der Schlüssel im Schloss und Marcuses Frau kam nach Haus.

Erica Sherover - „Ricky“ wurde sie von ihm und ihren Freunden genannt - war etwa vierzig Jahre jünger als Herbert Marcuse. Ich hatte sie schon in den vorhergehenden Jahren sowohl in Kalifornien wie in Bayern getroffen und einige Worte mit ihr gewechselt. Zunächst schien sie mir eine schüchterne und zurückhaltende Studentin zu sein, die aus tiefer Verehrung und Respekt den schon sichtbar vom Alter gezeichneten Philosophen auf Reisen in Europa begleitete. Erst später bin ich auf die starke Bindung zwischen der jungen Frau und dem alten Philosophen aufmerksam geworden. Und erst nach ihrer Heirat wurde mir klar, eine wie starke, eigenwillige und intellektuell anspruchsvolle Frau sie war. Sie hatte bei Marcuse eine Dissertation über den frühen Marx begonnen, genauer über dessen Debatte über das „Holzdiebstahlgesetz“. Diese Dissertation hat sie nach dem Tod ihres Mannes bei Habermas zu Ende geführt.

5. Ideologie des Todes: Die Stadt Berkeley, Heimstatt der berühmten „University of California“, wurde nicht auf fünf Hügeln gebaut sondern auf einem einzigen. Wenn man vom Tilden Park in den Berkeley Hills auf die Stadt herabschaut, erscheint sie wie eine schiefe Ebene, die im Süden in die Bucht ausläuft. Dieser Teil der Stadt heißt „Marina“. Zur Marina rechnet man in Berkeley nicht nur einen Yachthafen, sondern ein komplexes Ensemble, das aus einem tristen Park mit aufgeschütteten Hügeln und vertrocknetem 
Rasen besteht, auf dem Väter und Söhne dank des immer wehenden Windes die Drachen steigen lassen. Das Zentrum der Marina bildet eine Pier, die etwa eine Meile in die Bucht hineinragt. Seinerzeit gab es dort ein bekanntes Fischrestaurant. Das Restaurantgebäude gibt es heute noch, aber sein Management hat so oft gewechselt wie die ethnische Ausrichtung, die Zielgruppe und das Niveau. Heute beherbergt das achteckige, auf Pfählen im Wasser ruhende, sichtbar von den Winterstürmen zerzauste Holzgebäude ein Touristen-Restaurant. Den ursprünglichen Namen habe ich vergessen. Nicht vergessen kann ich, dass ich dort im Mai 1979 mit Leo Löwenthal und Herbert Marcuse, drei Monate vor seinem Tod, gegessen habe. Marcuse war allein nach Berkeley gekommen, um seinen alten Freund zu besuchen, den er „Leochen“ nannte.

Die beiden Männer waren schon da, als ich etwas verspätet eintraf. Sie waren heftig ins Gespräch vertieft. Leo Löwenthal erzählte ganz kurz, worüber sie so angeregt sprachen. Das Thema sei nicht mehr und nicht weniger als der Tod.

Wir saßen draußen auf der Terrasse, was selten möglich ist, weil es hier in der Regel entweder zu kalt, zu heiß oder zu stürmisch ist. Der Ausblick war atemberaubend. Direkt gegenüber erkannte man, immer noch ein wenig im Dunst, die skyline von San Francisco, zur Linken die Bay Bridge und rechts, gerade vom Nebel befreit, die majestätische Golden Gate Bridge. Löwenthal erriet meine Gedanken. Er mutmaßte, dass das Panorama wohl nicht zum Thema passe, erleichterte mir aber dann mit einem Scherz den Einstieg. Fast ausgelassen sagte er, dass der Tod des Menschen mit zunehmendem Alter wahrscheinlicher werde, sei eine verbreitete Erfahrung. Nur er und Marcuse seien besessen nicht vom Tode, sondern von der Idee, dass es in ihrem Fall eine Ausnahme von der Regel der Sterblichkeit geben könnte.

Marcuse lachte kurz auf und knüpfte dann im Gespräch an der Stelle an, wo ich sie unterbrochen hatte. Er bezog sich auf die vorgängige These von Löwenthal; letzterer, so erklärte er mir, hatte gesagt, der Umstand, dass der Mensch für sich allein sterbe, lege die Annahme nahe, dass das Sterben eines Menschen - ebenso wie seine Geburt - ein privatintimer Vorgang sei. Eine materialistische Deutung mache indes deutlich, wie sehr Tod und Sterben staatlich vermittelt seien. Das zeige sich nicht zuletzt im Kriege. Der dem Begriff „Opfer“ eingeschriebene Doppelsinn, der in der englischen Übersetzung deutlich werde, bezeichne als „victim“ und „,sacrifice“ zwei Formen jenes staatlichen Managements des Todes seiner Bürger.

Vor hundert Jahren noch - Marcuse und Löwenthal hätten es selbst zu Beginn des Ersten Weltkriegs erlebt - wurde von jedem Soldaten die Bereitschaft erwartet, sein Leben für sein Staatsvolk zu ,opfern“. Diese Erwartung sei ein Säkularisat christlicher Vorstellungen. Der Soldat opfert sich, damit sein Volk leben kann, ähnlich wie Christus sich am Kreuz geopfert hat. Diese unübersehbar sakrale Dimension in der gesellschaftlichen Deutung des Sterbens im Kriege sei heute fast restlos aus unserer politischen Kultur verschwunden. Heute spreche man von „Opfern“, meine damit aber Phänomene, die in der englischen Sprache mit dem Begriff ,victim“ treffender wiedergegeben werden: Wer als „victim“ stirbt, sterbe im Deutungshorizont einer staatlich kontrollierten Privatheit, in der der Tod seine soziale Relevanz nur noch habe als Material für die Versicherungen und die Statistik.

Marcuse sagte, er fühle sich vollkommen verstanden. Vielleicht sei der Doppelsinn im Begriff des Opfers, so spekulierte er weiter, nur der moderne Widergänger einer 
alten, noch aus der Antike stammenden Deutung. Im Abendland habe es nämlich zwei dominante Todesbilder gegeben, die zur Basis zweier konkurrierender Moralsysteme wurden. Zum einen sei dies die Lehre und die Moral der Stoa. Ihre Anhänger predigten die Hinnahme des Unvermeidlichen. „Stoisch“ ertragen sie das Bewusstsein ihrer Sterblichkeit. Leben und Tod sind zwei hier zwei völlig inkommensurable Zustände. So wie aus der Anschauung des Todes dem Leben kein Sinn abzuringen ist, vermag auch das Leben dem Tode keinen Sinn zu verleihen. Als Virtuosen im Ertragen der Kontingenz wirkten die Stoiker noch in der Moderne weiter.

Die andere Moral zeige sich in einer Verherrlichung des Todes. In der christlichen Perspektive sei der Tod das eigentliche Ziel des Lebens. Die Verherrlichung des Todes schon zu Lebzeiten sei zugleich eine machtvolle Ideologie. Marcuse nannte sie pointiert „Ideologie des Todes." Ideologisch sei sie, weil sie überflüssiges Leid, existenzielle Angst und grundlosen physischen Schmerz verkläre, den Herrschende den Beherrschten zufügen. Die dritte Position zwischen Stoizismus und Idealismus sei die Verknüpfung des Todes mit dem Begriff der Freiheit. Und dies sei die Position des Materialismus.

Löwenthal nickte zustimmend. Bevor er den Kellner an unseren Tisch bat, um die Bestellung aufzugeben, fügte Marcuse noch den folgenden Gedanken hinzu: Den Tod „besiegen“ zu wollen, müsse so lange als Anmaßung verstanden werden, wie damit gemeint sei, Menschen mit menschlichen, d.h. mit den technischen Mitteln der Medizin zur Unsterblichkeit zu verhelfen. Den „Tod besiegen“ könne indes auch bedeuten, dass der Mensch fähig wird, sein Sterben als das selbst gewählte Ende seines Lebens anzunehmen. Nur derjenige wird gut sterben können, der zuvor ein ,gutes Leben“ gelebt hat.

Inzwischen hatte die Mittagssonne den Dunst weggebrannt, kein Wölkchen trübte mehr das Blau des kalifornischen Himmels. Jetzt konnte sich der Lärm voll entfalten, der zuvor von den Windgeräuschen abgefangen wurde. Das Brüllen der Motoren der im Stau gefangenen Lastwagen bildete den Grundton, kontrapunktiert vom Geschrei der Möwen, dem Geknatter von Helikoptern und dem fernen Tuten der Schiffe, die vom Pazifik her in die Bucht einfuhren.

6. Wieder in Starnberg: Die Fortsetzung meiner Geschichte spielt nun wieder in Starnberg. Als die Zeichen sich verdichteten, dass Herbert Marcuse bald sterben würde, wurde seiner Frau Ricky und seinem Sohn Peter immer deutlicher, dass sie ein unausgesprochenes Versprechen kaum würden halten können - das Versprechen, dass er nicht auf deutschem Boden sterben und in deutscher Erde begraben werden sollte. Es blieb unklar, wer der Autor des Versprechens war. Es stand irgendwie im Raum. Es ergab sich aus der Tatsache, dass Marcuse als deutscher Jude aus Deutschland verjagt worden war und viele Mitglieder seiner Familie in den Todeslagern ermordet wurden. Ich erinnere mich an ein Gespräch mit Marcuse in den ersten Tagen im Starnberger Krankenhaus. Darin spielte er auf ein Gespräch mit Löwenthal an mit dem Inhalt, dass letzterer nur deshalb jedes Jahr unbeschwert nach Europa fahre, weil er wisse, dass er jederzeit wieder zurückkehren könne. Neben Marcuse war Löwenthal das einzige Mitglied des Frankfurter Kreises, der bewusst die Entscheidung gefällt hatte, nie mehr dauerhaft in Deutschland zu leben. Die Möglichkeit eines plötzlichen Todes in diesem Deutschland empfand er, so drückte er sich aus, als ein tragbares Restrisiko. Nun war diese Situation unvermutet rasch möglich, ja wahrscheinlich geworden. Solange Marcuse noch ansprechbar und bei Bewusstsein 
war, wagte niemand, das Thema anzurühren. Doch als er nicht mehr in der Lage war, diese Entscheidung selbst zu fällen, fiel die Last jenen zu, die ihm am nächsten standen.

Mir erschloss sich der Stellenwert der Entscheidung erst allmählich. Restlos durchsichtig wurde sie mir freilich nie. Denn sie war schon strittig im inneren Kreis der Familie, also bei den Söhnen, den Enkeln und bei seiner Frau. Ich hätte damals nicht einmal sagen können, welche tieferen Überzeugungen die Optionen der Familienmitglieder bestimmten. Denn zwischen ihnen sowie den jüdischen Freunden und Verwandten der Marcuses und „uns Deutschen“ gab es eine eigentümliche Befangenheit. Sie lag nicht einfach in der Luft; sie war entstanden nach einem langen Gespräch bei dem ersten Abendessen im Holzhaus. Neben einigen wenigen deutschen Freunden war die Mehrzahl der Anwesenden Amerikaner jüdischer Herkunft. Weil in diesen ersten Tagen weder das Englisch der Gastgeber, noch das Deutsch unserer Gäste gut genug war, um uns anspruchsvoll miteinander unterhalten zu können, unterhielt sich die Gruppe der amerikanischen Gäste in ihrer Muttersprache. Ihre Unterhaltung nahm deshalb vermutlich die Richtung an, die sie auch in unserer Abwesenheit angenommen hätte. Ein Gast aus New York hatte Angelika beiläufig gefragt, wann denn das Haus erbaut worden sei, in dem wir saßen. Nachdem Angelika mit großer Unbefangenheit „1933“ antwortete, gab es eine kleine Pause im Gespräch. Um die entstandene kleine Peinlichkeit zu vertuschen, wechselte der Gast aus New York sogleich das Thema. Mit einer gewissen Beliebigkeit fragte er die anwesenden Gäste nach dem Schicksal ihrer Familien. Es stellte sich erst allmählich heraus, dass mit Ausnahme der Gastgeber alle Anwesenden Kinder jüdischer Emigranten waren. Vielen ihrer Eltern, Verwandten und Geschwister war die Flucht aus Europa nicht gelungen. Sie wurden in den Lagern ermordet.

Es waren die späten 70er Jahre. In Westdeutschland war zum ersten Mal eine sozialdemokratische Regierung an der Macht. Sie konnte sich stützen auf den dramatischen Einstellungswandel einer neuen Generation. Es hatte zwar wie in jedem Jahrzehnt der bundesdeutschen Geschichte antisemitische Skandale gegeben. Doch immer weniger gaben sie Anlaß, am demokratischen Kern des neuen Deutschland ernsthaft zu zweifeln.

Und dennoch. Wie tief muss die Entfremdung gewesen sein, wenn - in der eigenen Wahrnehmung wie in der unserer Gäste - schon bei kleinen Anlässen wie der Nennung einer Jahreszahl sich zwischen ihnen und uns eine symbolische Mauer aufbaute, die „uns“ von ,ihnen“ trennte. Ich erinnere mich, dass ich verstohlen in den Gesichtszügen der Gäste nach jüdischen Merkmalen fahndete. Und einer von ihnen gestand mir nach einigen Wochen, dass er in den Physiognomie der anwesenden Deutschen wie in einer „Verbrecherkartei“ (so wörtlich!) gelesen habe. Obwohl das große Morden dreißig Jahre zurück lag, war „Unbefangenheit““ im Umgang mit dieser Geschichte noch immer unmöglich. Und so würde es lange bleiben. Die jeweilige „Befangenheit“ hängt davon $\mathrm{ab}$, auf welcher Seite der Trennlinie man lebt. Wer auf der Seite der Täter war, musste ständig gegen die Versuchung ankämpfen, die Vergangenheit zu „bagatellisieren.“ Ich weiß nicht, ob es auf jüdischer Seite die komplementäre Neigung gibt, die Vergangenheit $\mathrm{zu}$,dramatisieren“, wenn das überhaupt möglich ist.

Ich hatte damals in den Tagen, als Marcuse im Sterben lag, den Eindruck, dass Ricky, seine Frau, alles andere als gelassen war im Umgang mit deutschen Ärzten, Ämtern, Polizisten und Zöllnern. Sie sagte es nie explizit, aber hat mich deutlich spüren lassen, dass ihre Ungeduld mit deutschen Amtspersonen einem Generalverdacht entsprach. Sie 
hat mich in den letzten Tagen als Übersetzer mitgenommen, obwohl ihr Deutsch schon recht passabel war. Und sie gestand mir eines Tages, dass sie nicht meine sprachlichen Dienstleistungen so sehr schätze, als vielmehr mein Einfühlungsvermögen in die autoritären Neigungen der jeweiligen Kooperationspartner. So hat sie allen Ernstes unterstellt, dass die Ärzte im Starnberger Krankenhaus nicht nur inkompetent, sondern auch bösen Willens seien, als sie ihr ankündigten, dass es mit Herbert zu Ende gehe.

Vergeblich war auch ihr Versuch, Herbert Marcuse noch außer Landes zu schaffen. So wollte sie partout für den Sterbenden eine Sitzreihe in der ersten Klasse einer LufthansaMaschine buchen. Doch weder die Lufthansa, noch irgendeine andere Fluggesellschaft war bereit, den Sterbenden ohne ärztliches Attest zu transportieren.

7. Therapie und Theorie: In dem breiten Spektrum von Tätigkeiten und Talenten, denen Ricky - neben ihrer Sorge für Herbert Marcuse - selbst die größte Bedeutung beimaß, war die einer Psychotherapeutin. Es war die Tätigkeit als Gruppentherapeutin, die ihr in Berkeley schon vor ihrer Ehe mit dem berühmten Philosophen eine gewisse Prominenz verschafft hatte. Freilich waren Theorie und politische Praxis, die dieser Psychotherapie zugrunde lagen, weit entfernt von dem, was ein Laie sich darunter vorstellt. Angelika und ich haben erst später, nachdem wir längere Zeit in den USA gelebt hatten, gelernt, diese Therapie als eine typisch kalifornische Kulturerscheinung zu deuten.

Angelika wurde mit dieser Therapie gleich in den ersten Tagen von Rickys Präsenz im Holzhaus konfrontiert. Ihr Bild von Ricky wird immer vom dem Schock dieser Konfrontation bestimmt sein. Sie kam am späten Nachmittag nach Hause und hörte, als sie aus dem Wagen stieg, gellende Schreie. Sie rannte durch den Garten ins Haus, die Treppe hinauf in das Zimmer, in das sie Ricky und eine Münchener Freundin einquartiert hatte. Beide Frauen waren in einem Zustand großer Erregung. Gleichwohl entsprach das Maß der Erregung nicht dem Eindruck eines grauenvollen Ereignisses, den Angelika vom bloßen Höreindruck gehabt hatte. Die Frauen wischten sich mit großen Papiertüchern die Tränen ab und putzten ihre Nasen. Ricky sagte mit einer Stimme, die von weither kam und zugleich routiniert wirkte: „Darf ich Dich bitten, uns nicht zu stören, wir machen gerade, co-counseling' “ Das war Angelikas erster Kontakt mit der beruflichen Seite Rickys, die, das sollten wir rasch lernen, ihre Identität ausmachte, bevor sie „Herbie“ kennenlernte.

„Co-Counseling“ ist fundamental unterschieden von dem auf die individuelle Person zugeschnittenen „,medikalistischen“ Modell der Psychoanalyse und der Verhaltenstherapie. Weil in den Therapiegruppen jeder und jede Therapeut und Patient zugleich ist, ist es eine Gruppentherapie im Wortsinn. Dahinter steckt eine Theorie, die sich bestimmte Motive der kalifornischen Antipsychiatrie der 7oer Jahre sowohl auf der Ebene der therapeutischen Technik als auch der Metapsychologie zueigen gemacht hat. Stärker indes als spontane Sympathie war auf meiner Seite ein nachhaltiges Unbehagen, das ich gegen Rickys Lesart dieser Therapie und Theorie empfand. Ich konnte ihr folgen bei ihrer Prämisse, dass unsere psychischen Wundmale nicht Ausdruck einer individuellen Leidensgeschichte seien; das, was uns psychisch bedrücke, seien Auswirkungen von traumatischen Kränkungen, die wir als Angehörige unterdrückter Minderheiten in Gestalt von „rassistischen“, „,sexistischen“ oder „klassen-spezifischen“ Verletzungen erfahren haben. Mein Unbehagen richtete sich allerdings gegen Rickys Anspruch, dass dieses Konzept eine Lücke im Werk ihres Gatten schließe. 
Ich wusste aus einem früheren Gespräch bei einem gemeinsamen Abendessen bei den Löwenthals in Berkeley, dass Marcuse diesem Anspruch seiner Frau mit milder Herablassung begegnete. Seine Theorie sei eine „kritische“, sagte er knapp. Jeglicher Versuch, den Riss, den der Spätkapitalismus in der Seele von Menschen hinterlässt, mit einer Therapie „heilen“ zu wollen, sei ein gegen-revolutionäres Projekt. Rickys Versuch, seiner Kritik der Freudschen Metapsychologie unmittelbar eine Therapie aufzupfropfen, sei ein Teil des Problems, nicht seine Lösung.

Doch unabhängig von dem zwiespältigen Gefühl, das ich gegenüber therapeutischer Praxis und Theorie des „co-counseling“ empfand, wurde ich von Ricky in den letzten Tagen Herberts als ihr „coach“ oder ihr therapeutischer Widerpart ausgeguckt. Dabei lernte ich, dass die therapeutische Technik von suggestiver Einfachheit ist. Menschen sind nach dem Bilde dieses Ansatzes große, unermüdliche Lernmaschinen, die Freude daran empfinden, die Probleme dieser Welt zu lösen. Selbst belastende Erfahrungen werfen sie nicht aus der Bahn. Aber für jeden Menschen gibt es indes Grenzen des Zumutbaren. Aus der Traumatherapie wissen wir, dass es Erfahrungen gibt, die das Reaktionspotential jedes Menschen übersteigen. Eine psychische Störung, ein neurotisches Symptom entsteht, wenn nach einer schmerzvollen Erfahrung keine Gelegenheit ist, die negative Erfahrung kommunikativ zu bearbeiten. „Muster“ nannten Ricky und ihre Freunde die neurotisch verzerrten Charakterstrukturen, die hinterrücks dafür Sorge tragen, dass auch in zukünftigen Situationen Erfahrungen in diesem negativen Sinne immer wieder reproduziert werden. Dabei wisse die Soziologie ganz genau, entlang welcher Linien solche „Muster“ sich bilden. Ein beschädigtes Selbstbild treffe man vornehmlich in Gruppen, die wie etwa Frauen, Schwarze oder Angehörige unterer Schichten systematisch diskriminiert würden. Solche Praktiken würden noch bis zur Undurchdringlichkeit verstärkt, wenn Institutionen wie Passämter, polizeiliche Verfolgungsbehörden und Schulämter diesen „Mustern“ den Schein einer sekundären Angemessenheit verliehen.

Die Therapie, so Ricky, könne von jedem Laien gehandhabt werden. Sie besteht in der Ermutigung, das Leid auszusprechen, es expressiv aus sich herauszuschreien. Dem jeweiligen Therapeuten obliegt es, die Rückhaltlosigkeit dieser Expression zu überwachen. Entgegen der üblichen Neigung, ein weinendes, schreiendes Individuum zu trösten und zu besänftigen, muss man darauf achten, dass es ,,nichts bei sich behält“. Der „Patient“ ist hier im strengen Sinne nicht ein leidendes Individuum, das sich einem allwissenden und allmächtigen Therapeuten konfrontiert sieht. Vielmehr ist diese „co-counseling“ genannte Therapie eher ein Rezept für eine demokratische Willensbildung unterdrückter Gruppen. Im Schreien, Weinen und Klagen, das die Teilnehmer der Therapie wechselseitig evozieren, melden sich nicht die Qualen einer individuellen Person, sondern die Schmerzen der Gattung. Je authentischer ein Individuum „seine“ Qualen aus sich herausschreit, desto mehr befördert es die Emanzipation des Kollektivs, dem es zugehört.

Dieser therapeutische Imperativ, den leidenden Teil der therapeutischen Beziehung nicht im Wortsinn ,trösten“ zu wollen, fiel mir sehr schwer, als Ricky mich in den Tagen, da Marcuse im Sterben lag, bat, ihr ,,counterpart“ zu sein. Nicht nur, dass ich - Angehöriger einer protestantischen Kultur - peinlich berührt war von der ungehemmten Expression von Trauer. Noch schwerer fiel mir, sie jeweils noch zu krasseren Formen der Kundgabe von Trauer zu provozieren. 
Ricky war über alle Maßen verärgert über meine Unfähigkeit, mich den therapeutischen Regeln zu fügen. Sie hielt mir vor jeder Therapiesitzung einen eindringlichen Vortrag mit der Pointe, dass Akte der Tröstung und Beruhigung selbst einen Mechanismus darstellen, wie „Muster“ durch repressive Eltern und Erzieher geschaffen und verfestigt werden. Aber an dem Abend des 29. Juli 1979, der Abend des Tages, an dem Herbert Marcuse starb, war ich so sehr im Bann meiner eigenen Gefühle, dass ich trotz aller Ermahnungen alles falsch machte. Auf dem Höhepunkt ihrer Trauerklimax angekommen, war ich plötzlich nicht mehr imstande, als ihr „,coach“ zu fungieren. Ich musste einfach sagen, was ich dachte. Keine Macht der Welt konnte mich in dieser Situation davon abhalten, mir einen eigenen Begriff von Marcuses Sterben und Tod zu machen, auch wenn meine Äußerungen nicht ins therapeutische Erwartungsschema seiner Witwe passten.

Ich sagte, ich wisse, dass sie das, was ich zu sagen hätte, nicht hören wolle. Ich redete schnell, weil ich Angst hatte, dass sie mit ihrer messerscharfen Rhetorik zwischen meine Sätze springen und meinen Redeschwall unterbrechen würde. Ich könne, so gestand ich ein, ihren Umgang mit Herberts Sterben und Tod schwer ertragen. Er sei doch kein Mensch gewesen, der sein Leben nicht gelebt habe. Wirkliche, unerträgliche und existentielle Trauer sei nur legitim, wenn ein Mensch stirbt, der darin gehindert wurde oder nie die Chance hatte, das Potential, das er im Herzen und im Kopf habe, zu entfalten. Gewiss habe er mit vielen Widerständen und Gegnern sich auseinandersetzen müssen. Doch in den Jahren vor seinem Tod sei er einer der wichtigsten Philosophen und Gesellschaftstheoretiker der Welt gewesen. Ich würde bei aller Traurigkeit von ihr eine gewisse Dankbarkeit erwarten für das Geschenk, dass das Leben ihr mit Herberts Liebe, seiner intellektuellen und physischen Präsenz gemacht habe. Mir fielen plötzlich die Sätze ein, die Horkheimer in einem Kondolenzschreiben aus Anlass des Todes von Sophie Marcuse an ihren Witwer geschrieben hatte.

Ricky war blass geworden, als ich die Sätze zitierte. Sie entgegnete mir nicht ohne Schärfe, dass „Herbert“ über die Philosophie der Tröstung sehr aufgebracht gewesen sei. Sichtlich um Fassung ringend, sagte sie, sie respektiere meine Sichtweise. Und sie sei glücklich, wenn sie sich eines Tages ein Bild von Herbert zueigen machen könne, das meinem gleichkomme. Aber sie sei eben nicht primär seine wissenschaftliche Assistentin oder Hilfskraft gewesen, sondern seine Frau. Ich könne mir wohl nicht ihre Angst vorstellen vor der Einsamkeit der kommenden Nächte. Sie fühle sich verlassen von dem Mann, der ihr Partner, ihr Geliebter, Vater und intellektueller Leuchtturm gewesen sei. Sie wisse nicht, wie ihr Leben jetzt weiter gehen könnte.

In den Tagen nach Herberts Tod wohnte Ricky noch im Haus. Aber sie war - zusammen mit Peter - so sehr beschäftigt mit der Regelung von Herberts Bestattung und der Rückreise, dass kaum noch Gelegenheit blieb, über den Streit zu reden, der zwischen uns ausgebrochen war. Wir hatten nie mehr die Gelegenheit, darüber zu reden.

8. Jenseits der Sklavensprache: In der Nacht zum 29. Juni 1979, die Nacht, als Marcuse starb, war ich früh ins Bett gegangen. In den Nächten zuvor hatte ich mich bis zum Morgengrauen mit den Gästen unterhalten. Weil ich mich als Gastgeber dazu verpflichtet fühlte, harrte ich als letzter aus und räumte dann die Küche auf, bevor ich todmüde ins Bett fiel. Früh am Morgen klingelte im Wohnzimmer das Telefon. Es war Peter Marcuse. Sein Vater war gestorben. 
Peter erklärte ernst und konzentriert, dass man nicht so tun könne, als sei der Tote Privateigentum der Familie. Die erste Pflicht, der die Mitglieder und Freunde der Familie jetzt nachkommen müssten, sei die Informierung der Öffentlichkeit. Habermas habe den pragmatischen Vorschlag gemacht, die Presseabteilung des Suhrkamp Verlages, in dem die wichtigsten Bücher von Herbert erschienen waren, mit der Aufgabe zu betrauen. Peter hingegen wollte dies in Vorwegnahme des Willens von Ricky verhindern. Aber die Zeit war knapp. Wenn wir nicht selbst die Initiative ergriffen, würden es andere tun. Schließlich umfasste das Netzwerk von Verwandten, Freunden und Angehörigen auch etliche Medienvertreter, die über Herberts Tod berichten wollten. Peter bat mich deshalb,sofort ein kleines Redaktionskollektiv zu bilden, um einen Text für die Abendnachrichten des Zweiten Deutschen Fernsehens vorzubereiten.

Nun waren die meisten, derer ich in der kurzen Zeit nach Herberts Tod habhaft werden konnte, ebenso unerfahren und inkompetent wie ich selbst. Überdies war knapp die Hälfte des Redaktionskollektivs nur des Englischen mächtig. Ich hingegen kannte große Teile der Tradition, kannte Herbert Marcuse persönlich und sachlich und hatte schon Erfahrungen in der Welt der Verlage und der Redaktionsbüros gesammelt. So kam es schließlich, dass ich mich mit Bleistift, Radiergummi und Konzeptpapier bewaffnet an der Stirnseite des langen Wohnzimmertisches sitzen sah und ein Dutzend Augenpaare mich so erwartungsvoll anstarrten, als hätte ich den Vorsitz einer internationalen Fachkonferenz.

Es stellte sich heraus: Die Idee, unser Kollektiv mit dem Schreiben einer Erklärung zu betrauen, war keine gute. Nur die leicht Verrückten, die es zahlreich in Marcuses Gefolge gab, überwanden alsbald ihre Scheu, für die ,,bürgerlichen Medien“ eine Erklärung mitverantworten zu müssen. „Verrückt" waren diese Anhänger Marcuses schon deshalb, weil sie sich aus dem komplexen Weltbezug des Philosophen nur jeweils das heraus pickten, wozu sie einer zufälligen biographischen Prägung zufolge ohnehin eine gewisse Affinität hatten. In kurzer Zeit war der Wohnzimmertisch im Holzhaus Ort einer Art babylonischer Sprachverwirrung. Die einen sahen das Zentrum seiner Theorie im Marxismus, die anderen mochten ihn nur als Kritiker des sowjetischen Marxismus durchgehen lassen. Eine Amerikanerin aus Cornell wollte Marcuse noch posthum die Ehrenmitgliedschaft in der feministischen Bewegung antragen. Ein Freund und Bewunderer Rickys würdigte Herberts Beitrag zur Revision des Verhältnisses von sozialer Theorie und Psychoanalyse. Und ein Germanist aus New York wollte nur die neueren ästhetischen Arbeiten gelten lassen.

Die praktische Konsequenz dieser Art zu denken und zu schreiben war schlicht, dass der für die Abendnachrichten geplante Text in seiner Rohfassung ungefähr den fünffachen Umfang hatte, den Peter für die Erklärung empfohlen hatte. Jeder Versuch, den Text um einzelne Aspekte zu kürzen, rief sofort den Protest dessen herbei, der ihn vorgeschlagen hatte. Der nicht ohne Hohn gemachte Vorschlag, meine generalistischen Passagen zu streichen, hatte zur Folge, dass der Text sofort in seine Teilaspekte zerfiel. Inzwischen war die Hälfte der Zeit, die wir zur Verfügung hatten, verstrichen. Bis zu den Abendnachrichten blieben noch zwei Stunden.

Nach dem Hinweis auf die knappe Zeit schwiegen alle für einige Sekunden. Das Schweigen ging in ein Lauschen über. Denn aus der Diele, nur durch die Küche vom Wohnzimmer getrennt, kam der Klang einer Stimme, die alle kannten. Es war die leicht heisere, sirrende Stimme von Rudi Dutschke. Dutschke war schon vor drei Tagen hier 
gewesen, musste aber wieder nach Berlin zurück. Jetzt war er auf einen Anruf von Peter, der ihn vom Tod Herberts unterrichtete, zurück nach Starnberg geeilt.

Marcuse und Dutschke waren durch eine tiefe Freundschaft verbunden. Von außen besehen war es eine Freundschaft, die sich aus geradezu unwahrscheinlichen Affinitäten ergab. Sie waren trotz ihres großen Altersunterschieds gleichermaßen charismatische Sprecher der internationalen Studentenbewegung. Wie andere Revolutionäre auch waren sie im Lande ihres Ursprungs nicht wohl gelitten. Marcuse hatte zusammen mit anderen Mitgliedern der Frankfurter Schule 1933 vor den Nazis fliehen müssen. Dutschke wurde 1968 Opfer eines Attentats, an dessen Spätfolgen er dann 1979 starb. Dieses Attentat war nur der Gipfel einer ganzen Serie von Drohungen und Einschüchterungen, die nicht nur von Privatpersonen kamen, sondern auch von Vertretern der Exekutive und der Boulevardpresse. Wahlverwandt waren Marcuse und Dutschke auch durch die Ähnlichkeiten ihrer theoretischen und politischen Position. Beide plädierten für einen humanen und demokratisch geläuterten Sozialismus. Beide waren aus unterschiedlichen biographischen Gründen schärfste Kritiker des institutionalisierten Marxismus, sei er sozialdemokratischer oder bolschewistischer Provenienz. Beide waren sich einig in der Kritik sektiererischer Strömungen in der Studentenbewegung. Beide waren von ihrer Herkunft her Brandenburger und durch die politische Kultur der Stadt Berlin unverkennbar geprägt. Und beide starben innerhalb der zweiten Hälfte des Jahres 1979.

Ich unterbrach sogleich die Sitzung, um Freunden und Bekannten Gelegenheit zu geben, Dutschke zu begrüßen. Natürlich fragte er nach dem Sinn und Zweck der eigentümlichen Versammlung. Die Bitte, uns doch mit seiner politischen und medialen Erfahrung zu unterstützen, mussten wir gar nicht äussern. Die Zeit, die Dutschke auf Ricky und Peter zu warten hatte, die offenkundig in Verhandlungen mit dem Beerdigungsinstitut standen, wolle er gern nutzen, um die Erklärung zu schreiben. Ich las ihm unsere Notizen vor, übrigens mit stockender Stimme, weil mir erst im Akt des Vorlesens meine Hilflosigkeit so recht deutlich wurde. In einer Pause, die ich mir nahm, um einen Rest vom kalt gewordenen Tee zu trinken, unterbrach Dutschke mich rüde. Er sagte zur Charakterisierung des Textes nur kurz „Sklavensprache“. Das sei alles akademisches Eiapopeia, Ausdruck des vorauseilenden Gehorsams gegenüber den herrschaftlichen Instanzen der Gesellschaft.

Er formulierte aus dem Stand einen Gegenentwurf. Leider ist die Mitschrift der von ihm verfassten Erklärung nicht mehr auffindbar. Ich kann nur noch sinngemäß zitieren: Herbert Marcuse war ein deutsch-jüdischer Philosoph, der zusammen mit seinen Weggefährten von den Nazis 1933 aus Frankfurt verjagt wurde. Er sei ein radikaler Mensch gewesen, der sein ganzes theoretisches und politisches Leben der Realisierung der Freiheit und besonders den dafür erforderlichen materiellen Bedingungen gewidmet habe. Das Wort der „Utopie“ habe bei ihm nie jenen denunziatorischen Beiklang gehabt, der ihm in der öffentlichen Rede neuerdings anhafte. Ein Leben in Würde und materieller Sicherheit für jeden sei möglich. Herrschaft im Spätkapitalismus bestünde eben darin, diese Wahrheit zu unterdrücken. Zum ersten Mal in der Geschichte der Gattung hätten die technische und die ökonomische Entwicklung ein Niveau erreicht, das ein Leben in Würde und Freiheit für alle Mitglieder der menschlichen Gemeinschaft möglich mache. Zugleich sei die Politik in der ganzen Welt darauf konzentriert, die Menschen durch 
immer perfekter werdende autoritäre Kontrollen davon abzuhalten, diese weltgeschichtliche Chance zu erkennen und praktisch zu ergreifen.

Alle standen auf und klatschten Beifall. Es war mehr eine Rede gewesen als ein redaktioneller Beitrag. Es war nicht nur die Spontaneität seines Auftretens, sondern die eigentümliche Aura des Beschädigten, die seinem Beitrag den nachhaltigsten Eindruck sicherte. Eine Freundin hat dann die Rede Dutschkes mit seiner Hilfe aufgeschrieben und an die ,Tagesschau-Redaktion“ telegraphiert.

Um 20 Uhr saßen wir dann alle voll Spannung vor dem Fernsehgerät. Die erste Nachricht, die zusammen mit einem Bild und einem kurzen Film von dem FU-Kongress kam, war dem Tode von Herbert Marcuse gewidmet. Es war eine faire und „,ausgewogene“ Berichterstattung. Der konservative Standardvorwurf, Marcuse habe der RAF in die Hände gespielt, wurde gar nicht erwähnt. Doch Dutschkes Redebeitrag war nicht dabei.

Im Laufe des Abends gab es dann die Wiederholung einer vor einem Jahr gesendeten Dokumentation über das Leben, das Werk und die politische Wirkung von Herbert Marcuse. Ihr Autor war der damals noch jugendliche Ulrich Wickert, der später für lange Jahre Moderator der „Tagesthemen“ werden sollte. Ulrich Wickert war und ist ein Exempel für eine Generation von 68ern, deren Karriere Zeugnis dafür ist, dass es ein ,richtiges Leben im falschen“"geben kann. Aber auch dieser kluge Redakteur konnte sich - am Ende der Sendung - die Geste eines populistischen Realismus nicht verkneifen, indem er an Marcuse mit Augenzwinkern, das an seine Zuschauer adressiert war, die Frage richtete, ob er, kritischer Geist, der er sei, denn tatsächlich an die Existenz von Ideen glaube. Diese Sequenz des Dokumentarfilms war bei einem Spaziergang vor einem Jahr an der Küste Kaliforniens aufgenommen worden. Die Sonne war gerade am Horizont verschwunden, der Wind hatte nachgelassen und die Brandung hatte sich etwas beruhigt. Erst jetzt fand das Auge des Betrachters die Ruhe, um das schöne Spiel der Farben wahrzunehmen, das die Sonne noch nach ihrem Untergang mit den Wolken trieb. Herbert Marcuse blieb stehen, wies irgendwie müde auf das Spiel der Farben am Horizont und sagte dann so leise, dass Wickert das Mikrophon ihm ganz nah unter die Nase halten musste: ,Wie verblendet muss man eigentlich sein, wenn man angesichts solcher Schönheit an der Existenz von Ideen zweifelt?““

9. Die Sterbefeier: Über die „Sterbefeier“ für Herbert Marcuse, die am nächsten Tag in der Nähe des Holzhauses in Starnberg stattfand, ist die Quellenlage karg. Neben der leibhaften Erinnerung der Beteiligten gibt es eine Reihe von alten Fotos, die seit einigen Jahren auch im Netz einsehbar sind. Die Feier fand statt auf einer Lichtung im angrenzenden Wald. $\mathrm{Zu}$ dieser Lichtung gelangt man auf einem Trampelpfad, der über einen vermoderten Zaun in den lichten Wald führt. Dort stellten sich die etwa zwanzig Trauernden unter der zwar freundlichen, aber bestimmten Autorität Rickys zu einem Kreis auf. Für Nordeuropa vor der Klimakatastrophe war es ein durchschnittlich warmer Sommertag. Der Lichteinfall in den Bäumen, den man auf den Fotos erkennt, zeigt, dass die Feier am späten Nachmittag stattfand. Für einen zufälligen Beobachter, der plötzlich in die Szene im Wald geplatzt wäre, wäre kaum ersichtlich gewesen, um welch ein Ritual es sich handelte. Die Kleidung jedenfalls hätte keinen Hinweis gegeben. Mit Ausnahme von Jürgen Habermas, der ein Jackett mit weißem Hemd und schwarzer Krawatte trug, waren alle 
anderen leger gekleidet, so als wollten sie den sakralen Anlass der denkwürdigen Veranstaltung dementieren.

Mit einem gewissen Befremden registrierte ich, dass Ricky ein Kofferradio in Stellung brachte. Seinerzeit nannte man diese riesigen Kisten „Ghetto-Blaster“. Marcuse hatte sich in mehreren Interviews, ohne Rücksicht auf politische Korrektheit, oft mokiert über die Schwarzen, die in ihren Ghettos diese dröhnenden Musikmaschinen auf ihren Schultern spazieren führten. Doch Ricky hatte zur Eröffnung und zum Abschluss der „Sterbefeier“ geplant, den berühmten Kanon von Pachelbel in D-Dur für Streicher abzuspielen. Der „Kanon“, von dem ein gutes Dutzend an Bearbeitungen existiert, wird durchweg bei Beerdigungen gespielt.

Als die letzten Takte des „Kanons“ verklungen waren, begannen die Reden. Dutschke kommentierte einen Text von Robert Kurz, Harold las aus Ingeborg Bachmanns ,Sonnenschiff“. Osha Neumann, der ältere Stiefsohn von Marcuse, liess bis zuletzt offen, worüber er sprechen wollte. Auch Goethes Gedicht „Über allen Gipfeln ist Ruh“ und Nietzsches „Alle Lust will Ewigkeit“" wurden vorgetragen. Moishe Postone und Ricky sprachen Kaddisch. Habermas beschloß die Zeremonie mit einem eindrucksvollen Kommentar über das Schlußkapitel von Marcuses Buch „Triebstruktur und Gesellschaft“.

Michael Neumann ist der jüngere Stiefsohn von Herbert Marcuse (und der leibliche Sohn von Franz Neumann, des berühmten politischen Wissenschaftlers, dem wir eines der besten Bücher über die politische Ökonomie des Nationalsozialismus verdanken). Michaels Thema auf der Sterbefeier war die „Permanenz der Kunst“, Titel der letzten Schrift von Herbert Marcuse. Michael erinnerte in seinem Kommentar an eine oft übersehene Wende im Denken seines Stiefvaters. Dieser hatte angesichts der mit Blumen geschmückten Barrikaden des Pariser Mai, angesichts der politischen Grafitti auf den Mauern von West-Berlin und der „murals“ genannten, an Diego Rivera geschulten Wandmalereien geglaubt, dass es kulturelle Formen von Kunst geben könne, die in die Lebenswelt der spätliberalen Gesellschaft eintreten, ohne an systemsprengender Kraft einzubüßen. Erst in seinem letzten Buch hat er diese Ansicht zurückgenommen und das Emanzipationsversprechen der Kunst eng mit ihrer ästhetischen Form verknüpft.

Obgleich Herbert Marcuse „nur“ der Stiefvater von Michael und von Thomas war, kann man sagen, dass beide Früchte nicht weit vom Stamm fielen. Beide hatten einen der Charakterzüge, die beim Stiefvater in harmonischer Ungeschiedenheit koexistierten, radikal ausgebildet. Michael war Philosophieprofessor an der Universität geworden und repräsentierte somit die akademischen Interessen der beiden Väter. Osha hingegen war ein „radical“, eine Art alternativer Berufspolitiker. Er praktizierte als Rechtsanwalt und vertrat ausschließlich politische Demonstranten, Opfer polizeilicher Übergriffe und Obdachlose. Es passt in seinen Habitus, dass er zugleich ein in Berkeley stadtbekannter Künstler, ein „Muralist“ war. „Murals“ sind großflächige, sehr expressive Wandmalereien, in denen Episoden des Kampfes der verelendeten Landbevölkerung gegen Polizei und Militär dargestellt sind. Osha hatte sich spezialisiert auf die Darstellung des Kampfes der Studenten gegen die kalifornischen Ordnungskräfte.

Ricky hatte Osha frei gestellt, ob und worüber er reden wollte. Er sprach lebhaft und ohne jede Interpretation von einem Baum in Oaxaca (Mexiko). Der Baum, ,,arbol del tule“ genannt, steht mitten auf dem zentralen Platz der Stadt. Ungewöhnlich ist der Umstand, dass der Baum allen Vögeln der Stadt Nacht für Nacht ein Obdach bietet. Täglich exakt 
um 17 Uhr am Nachmittag (man kann die Uhr danach stellen) versammeln sich Tausende von Vögeln in seinem Geäst. Die Blätter und Zweige bilden ein undurchdringliches Dickicht, so dass man die Zahl der versammelten Vögel nur an der Lautstärke ermessen kann. Um 17 Uhr beginnt das lebhafte Gezwitscher, das sich in Minutenrhythmen zu einer ohrenbetäubenden Kakophonie entwickelt, die selbst an Markttagen den Straßenlärm noch übertönt. Aber um 18 Uhr (wieder könnte man die Uhr danach stellen) bildet sich der Lärmpegel zurück. Für einige Sekunden schilpt hier und da noch ein einzelner Vogel; vielleicht träumt er schon, oder er kann nicht schlafen. Dann ist es still auf dem Zocalo. - Osha verzichtete darauf, seine kleine Geschichte zu interpretieren. Er verließ sich wohl darauf, dass jeder von uns für sich imstande sein werde, die Geschichte mit je eigenem Sinn zu versehen.

Peter Marcuse trug dann als letzten Akt ein bewegendes langes Gedicht vor, das sein Vater während des Sterbens seiner zweiten Frau (Inge) geschrieben hatte. Inge Marcuse war sieben Jahre zuvor gestorben.

Warum fangen wir an, uns Gedichte zu schreiben?

(Andere schreiben Gedichte am Anfang)

Weil wir jetzt nicht mehr unter dem Gesetz des Alltags stehen. Sondern unter höherem Gesetz, dessen Sprache nicht mehr des Alltags ist, nicht mehr Prosa, obwohl die Worte dieselben sind,

Wenn wir Liebe sagen, wissen wir, dass der Tod stärker als die Liebe, dass die Liebe traurig ist Tod-traurig, und kann nicht anders sein.

Denn alle Lust will Ewigkeit

Und kann es nie sein,

Die Liebe sei stark wie der Tod.

Diesen Blödsinn

Habe ich nie geglaubt. Auch Erinnerung

Hilft nicht:

Sie ist todtraurig. Auch die Blumen nicht, Deine Blumen, unsere Blumen, die du für mich gehegt hast.

Denn sie sind Dein Bild und

Und Du bist nicht mehr da..

Dass es dich nicht mehr gibt, ist unvorstellbar

Vorstellbar ist nur

Dass es mich auch nicht mehr gibt.

Bald.

Manchmal glaube ich, dass du allein sein willst, um Dich mit dem Tod zu verständigen, 


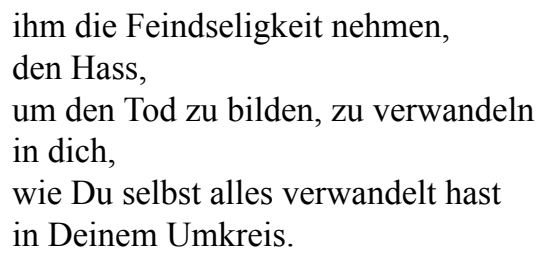

Aber dann müsste der Tod deine Augen heben,

Deine Seele,

er müsste wie Du sein,

voll Liebe,

Die kleinen Finger,

abgemagert, schwach,

wie die eines Babys

tasten über das Gesicht

zitternd:

ob es noch da ist?

Die hellgrünen Augen

Sehen wohl noch aber

Sagen nichts mehr

Die Stimme gibt keine Antwort mehr.

Todesschlaf in den Tod.

\author{
Alles Liebe, \\ alles Süsse, \\ alle Kraft \\ sind noch in diesem Körper \\ sie haben ihn aufgezehrt. \\ Wo sind sie jetzt? \\ Man hat den Körper hinausgetragen \\ Den Menschen \\ Die Geliebte \\ - wie ein grosses Stück Holz, \\ zum verbrennen. \\ Das Ende.
}

10. Der Anfang vom Ende der Geschichte: Wer verwundert oder gar empört die Frage stellt, wie es kommen konnte, dass für bald zweieinhalb Jahrzehnte niemand den Aufenthaltsort der Urne mit Marcuses Asche kannte und es deshalb auch keinen Ort gab, wo man des Philosophen hätte rituell gedenken können, wird keine befriedigende Antwort bekommen. Am Anfang stand das Problem, dass als Ricky nur wenige Jahre nach ihrem Ehemann starb, sich Marcuses Sohn Peter nicht hinreichend klar war, dass nun die Verantwortung für die Asche auf ihn übergegangen war. Was folgte, war eine Kette von Zufällen und auch Folge einer gewissen Nonchalance in Fragen der „Pietät“, für die der Tote sicher am meisten Verständnis gehabt hätte. 
Die Geschichte der Wiederentdeckung der Urne ist von ähnlichen Zufällen begleitet wie ihr Verschwinden. Es war ein Philosophiedozent aus Amsterdam namens Michel Meynen, der, angeregt von einem seiner Studenten am 19. Dezember im Jahr 2003 an Harold Marcuse eine E-mail schrieb und unverblümt nach dem Ort fragte, wo Herbert Marcuse eigentlich begraben sei. Harold antwortete so prompt, als hätte er auf die Gelegenheit gewartet: ,This is an interesting question. To the best of my knowledge, he was cremated in Austria, and his ashes are in an urn in New Haven, Connecticut, USA. They have not been buried. I'll check into this, and let you know if I find out more." In Kopie schickte er die mail auch an seinen Vater Peter.

Die Geschwindigkeit, mit der Harold auf die Frage reagierte, war verblüffend. Weist sie doch darauf hin, dass er durchaus eine Ahnung hatte, dass es die Urne noch gab und es im Familiengedächtnis der Marcuses sogar konkrete Hinweise gab, wo man suchen müsste. In seiner Antwort bestätigte Peter die Vermutung Harolds über den Aufenthaltsort und fragte, ob er tätig werden solle. Warum es gerade dieses Anstoßes eines namenlosen Studenten aus Holland bedurfte, um die Geschichte der vagabundierenden Asche zu vollenden, wissen wir nicht. Vielleicht hat es im Laufe der Jahre von 1979 bis zum Jahre 2003 viele solcher Anfragen gegeben, auf die es keine Reaktion gab? Und ebenso wenig wissen wir um den Ort der Urne im kollektiven Unbewussten der Marcuse-Familie. Doch von nun an nahm Harold, der Enkel von Herbert, das Heft in die Hand. Er setzte durch, dass die Asche seines Großvaters an einem für die Öffentlichkeit zugänglichen Ort begraben werden und dass dieser Ort Berlin sein sollte.

Nachdem die Urne wieder im unmittelbaren Besitz der Familie war, richtete Harold auf seiner website ein „Gästebuch“ ein, um den Debatten der Familie über die Zukunft der Asche ein Forum zu geben. Auch etwa 40 akademische und politische Anhänger wurden aufgefordert, ihre Ansichten und Vorschläge zu bekunden. Unklar ist, welchen Stellenwert diese familienexternen Meinungsäußerungen für Harold hatten. Ein einmütiges und entschiedenes Votum der Familie in der einen oder anderen Richtung hätte Harold gewiss respektiert. Und es ist zweifelhaft, ob er den gleichen Respekt für Vorschläge von Freunden aufgebracht hätte. Dennoch war ihm die Debatte wichtig. In verschiedenen Briefstellen betont er immer wieder, dass der tote Philosoph - zumal nach so vielen Jahren - kein exklusiver Besitz der Familie mehr war.

Die Stellungnahmen in dem „Gästebuch“ sind alles andere als eindeutig. Selbst die Frage eines durch die Zeit gelockerten privaten Verfügungsrechts der Familie über die Asche ist Gegenstand einer durchaus kontroversen Diskussion. Gerade ehemalige Kollegen und Weggefährten Herbert Marcuses hätten es lieber gesehen, wenn die Familie ihre Dispositionen nicht-öffentlich und in aller Diskretion getroffen hätte. Davon abgesehen gab es eine große Variationsbreite. Fast jede Stellungnahme bezog sich auf den Umstand, dass Marcuse aus Deutschland von den Nazis verjagt worden war. Aber die Konsequenzen daraus waren unterschiedlich. Die Meinung Harolds in diesem Punkt ist bekannt. Er betonte, dass es darauf ankäme, auf der Welt einen Platz zu finden, wo die Anhänger seines Großvaters seiner gedenken könnten: „Well, how about we bury them (,the ashes“, H.D.) somewhere where people can visit them? I think Berlin would be appropiate, and I think there is something fitting in his remains returning there. He was, after all, quintessentially a German intellectual, even if he decided never to return permanently while he was alive. Why give the Nazis the satisfaction of having purged the 
country even of the remains of some of its finest intellectuals? Has'nt Germany finished its 40 years in the desert?"

In einem anderen Brief verweist Harold auf die Veränderungen in der politischen Mentalität der Deutschen. Er vergleicht das zeitgenössische demokratische Bewusstsein mit dem vor 25 Jahren und bekundet die Auffassung, dass Deutschland einen Prozeß politisch-moralischer Läuterung hinter sich gebracht habe: „The Germans have come a long way - in a positive sense - from when they drove Herbert and the rest of their unwanted citizens from their country in the 1930s and 40s. When Herbert died in 1979, they had not come nearly as far - that is what my own research as a historian is about; so I think I can speak with authority on that ... Thus I would say it is a time for healing and making whole again. Herbert, Angela Davis, and Erica Sherover, all went back to study and teach. At that time no lasting bridges were built; Germany was not ready. But now I think the country is ..."

Den direkten Kontrapunkt zu dieser Position vertritt seine Schwester Irene mit der in der Presseberichterstattung oft zitierten Begründung: „I have rather strong feelings that my grandfather, who was forced to leave his country, should not be returned there, and also that there are already the ashes of enough jews mixed with German soil ..."

In der Tat entwickelte sich in den 80er Jahren eine erstaunliche Dynamik in der öffentlichen Reflexion der NS-Vergangenheit in Deutschland. Vieles kam zusammen in dieser Zeit, vor allem ein unübersehbarer Generationswechsel sowohl in der politischen Elite wie im Wahlvolk. Die Alterskohorten, die das Nazi-Regime verantwortlich getragen oder stumm ertragen hatten, wurden in der demographischen Zusammensetzung der deutschen Bevölkerung allmählich zur Minderheit. Die 80er Jahre in der Bundesrepublik waren gespickt mit zeitgeschichtlichen Ereignissen, die der deutschen Öffentlichkeit eine eine kollektive Reflexion über ,jene zwölf Jahre“ immer wieder aufnötigten. Den entscheidenden Lackmustest auf die Stabilität der westdeutschen Demokratie bildete indes die deutsche Wiedervereinigung. Die innerhalb der liberalen Intelligenz im In- und Ausland verbreitete Befürchtung, dass die Vereingung Deutschlands zum Auslöser eines neuen deutschen Nationalismus würde, erwies sich als falsch.

11. Die Beerdigung der Asche: Es war ein heißer, das öffentliche Leben lähmender Sommertag, als im Berliner Osten die sterblichen Überreste von Herbert Marcuse auf dem Dorotheenstädtischen Friedhof endgültig zu Grabe getragen wurden. Ein kalendarischer Zufall wollte es, dass Herbert Marcuse, fast auf den Tag genau, vierundzwanzig Jahre zuvor in Bayern gestorben war. Fast wiederum auf den Tag genau 36 Jahre zuvor war er die Zentralfigur auf dem legendären Kongress über das „Ende der Utopie“ in der Freien Universität zu Berlin.

Im Kontrast zum fast hermetischen Schweigen über den Verbleib seiner sterblichen Überreste fanden die Tage vom 16. bis zum 19. Juli 2003 im grellen Licht der massenmedialen Aufmerksamkeit statt. Nicht nur die Feuilletons der großen deutschen Tageszeitungen, sondern auch die New York Times, Le Monde, El Pais, La Republica berichteten ausführlich über die Umstände der Beerdigung. Besonders aber die Zeitungen in Berlin, der Tagesspiegel, die Berliner Zeitung, die taz und die WELT überboten sich in atmosphärisch dichten Schilderungen. Die unkonventionellen, ja grotesken Umstände von Marcuses Tod, der Einäscherung, die Irrfahrt der Urne und schließlich ihre endgültige 
Beerdigung auf einem kleinen, zentral gelegenen städtischen Friedhof, auf dem viele Künstler und Philosophen bestattet sind, waren ein sehr dankbares Sujet für die Kommentatoren der Hauptstadt-Zeitungen.

Peter und Harold Marcuse, der Sohn und der Enkel, hatten sich bei der Suche nach einer würdigen Grabstätte auf ein Netzwerk von Freunden und Unterstützern verlassen können, das sie beide seit der Wende geknüpft hatten. Besonders der Kontakt zum Kultursenator Thomas Flierl (von der PDS) erwies sich als sinnvoll. Er hatte Einfluss genug, um dem Philosophen ein Ehrengrab zu verschaffen. Es ist zwar klein, nämlich nur ein Meter im Quadrat, aber der Platz auf dem Dorotheenstädtischen Friedhof ist ähnlich knapp wie der Wohnraum im Süden Manhattans. Gewöhnlichen Sterblichen bleibt eine solche Ruhestätte meist versagt. Auf den Grabsteinen des kleinen Friedhofs sind hie und da grosse Namen zu lesen: Hegel, Fichte, Brecht, Helene Weigel, Heiner Müller, Rudolf Bahro. Angesichts dieser illustren Schar kam manchen Journalisten die Rede von einer Rückkehr ins ,alte sozialistische Europa“ in den Sinn. Nur Arno Widmann von der Berliner Zeitung stellte diese suggestive Deutung der letzten Ruhestätte des Philosophen behutsam in Frage. Mit intimer Ortskenntnis schrieb er: „Sein Grab liegt nicht neben denen von Fichte und Hegel. Er liegt nicht bei Bert Brecht, Rudolf Bahro oder Hans Mayer. Es liegt gegenüber dem von Rudi Strahl, dem erfolgreichsten Komödienautor der DDR. Auf dem Grabstein des im Mai 2001 gestorbenen Rudi Strahl steht: ,Lasst uns die nächste Revolution in einem August beginnen. Das hätte Marcuse sicher auch gefallen. ““

Peter Marcuse, der Sohn des Philosophen, liess es sich nicht nehmen, die Urne mit der Asche seines Vaters auf ihrem letzten Weg zu tragen. Das Packpapier, in das sie eingeschlagen war, trug noch die Frachtnummer und den Sticker „Achtung Aschenurne pietätvoll behandeln“. Das Urnenpaket hatte er im Rucksack als Handgepäck aus Connecticut nach New York mitgebracht. Er berichtete, dass die Sicherheitsbeamten am John F. Kennedy-Flughafen in New York keinerlei Anstoß an der Urne nahmen. Die Ankunft in Deutschland hingegen gestaltete sich etwas schwieriger. Peter wurde von den Grenzbehörden ebenso behutsam wie streng darauf hingewiesen, dass er die Urne mit der Asche nicht eigenhändig zum Friedhof bringen dürfe. Weil der deutsche Staat den Bürgern die Fähigkeit zu einem pietätvollen Umgang mit ihren Toten wohl nur begrenzt zutraut, neigt das deutsche Recht dazu, die Anverwandten der Asche ihrer Liebsten zu enteignen. So schiebt sich zwischen die Lebendigen und die Toten ein Wall von Auflagen, die den Hinterbliebenen deutlich machen, dass der teure Tote ihnen nicht mehr gehört. Übrigens haben diese strengen Pietätsregeln Geltung in allen Ländern, die im Mittelalter von der Pest gegeißelt wurden. Ihren rationalen Kern hat die Pietät somit im Ansteckungspotential von Leichen. Peter durfte die Urne also sofort nach der Ankunft einem autorisierten Bestattungsunternehmer übergeben, der sie dann am nächsten Tag mit dem Leichenwagen zum Friedhof in der Dorotheenstraße chauffierte.

Keiner der zahlreichen Zeitungsberichte vergisst die Erwähnung des spektakulären Leichenwagens Marke Cadillac, Baujahr 1957. Mit seiner Fracht teilte der Wagen den eigentümlichen Charme eines Wiedergängers. Der Wagen war schon abgemeldet gewesen. Er wurde eigens für die Fahrt der Asche des Philosophen noch einmal aus dem Berliner Verkehrsmuseum requiriert und flott gemacht. Und auch der alte Cadillac hatte ein bewegtes Leben hinter sich. Er hatte die sterblichen Überreste von Marlene Dietrich zu ihrer letzten Heimstatt gefahren. Diese Nachbarschaft hätte Marcuse gewiß auch gefallen. 
Freilich war diese letzte Prunkfahrt nicht die Idee der Marcuse-Familie selbst gewesen. Die Anmietung des extravaganten Wagens war auf Initiative eines Kamerateams geschehen, das eine umfassende Dokumentation aller Vorgänge um die endgültige Bestattung vorbereitet hatte.

Ursprünglich war die Beerdigung für Samstag, den 19. Juli 2003 vorgesehen. Sie fand dann kurzfristig einen Tag früher statt, weil die Gewerkschaft der Totengräber ein Verbot der Beerdigung an Samstagen durchgesetzt hatte. Es gab keinen Zeremonienmeister, keine Absprache über besondere Rituale und keine traditionsbewährte Liturgie bei der Grablegung der Urne. Für kurze Zeit übernahm einfach der Friedhofsangestellte die Initiative. Er klaubte die Urne aus dem Fond des Wagens und ging dann mit würdigem und gemessenem Schritt den kurzen Weg vom Parkplatz bis zum Grab. Ihm folgte planlos und etwas unentschlossen die bunte Schar der Familienmitglieder, Politiker, Journalisten und der vielen früheren Anhänger. Angelika erinnert sich bis heute an ihr Erschrecken über den Umstand, dass viele seiner Schüler und Gefolgsleute dank der inzwischen verstrichenen 24 Jahre selbst an der Schwelle zum Greisenalter standen; und sie berichtete, dass sie sich die Vorstellung kaum abgewöhnen könne, dass die 68er für immer eine Jugendbewegung seien.

Marcuses Sohn Peter hielt eine kurze Ansprache. Er leitete sie ein mit einem kleinen Shakespeare-Zitat: „We have come to bury my fathers ashes, we have not come to bury him.“ Die Wahl des Zitats war rhetorisch geschickt. Denn die Beerdigung der Urne hätte leicht als endgültige Grablegung der kritischen Theorie gedeutet werden können. Allzu leicht hätte man sich eine Argumentationslinie vorstellen können, die die Parallele zieht zwischen dem langen Vergessen der Urne und dem Verblassen des geistig-politischen Vermächtnisses des Philosophen. Das Argument war auch nicht aus der Welt zu bringen mit Peters trotziger Versicherung, ,dass der Kampf gegen Unterdrückung und Ausbeutung weitergeht"“.

Manche der Anwesenden fühlten sich wohl an eine ähnliche Situation erinnert. Einige Jahre zuvor war das in Stammheim einsitzende RAF-Mitglied Holger Meins an den Folgen eines Hungerstreiks gestorben. Dutschke, dem bis dahin niemand Sympathie für die Strategie des bewaffneten Kampfes hätte nachsagen können, hatte am Grab von Holger Meins die Faust gereckt und gerufen: „Holger, der Kampf geht weiter“. Peter Marcuse hatte in vermutlich unbewusster Anlehnung an diese Geste gesagt, die Botschaft, die sein Vater den versammelten Weggenossen hinterließe, sei in einem Wort zusammenzufassen und laute ,weitermachen“. Das war übrigens das einzige deutsche Wort in seiner auf englisch gehaltenen Rede. Dass er gleichwohl etwas anderes im Blick hatte als Holger Meins und wohl auch Rudi Dutschke, erschloß sich aus der Sprache des Körpers. Während der gesamten Zeit seiner Ansprache hatte er die Hände in den Hosentaschen. Und selbst als er die Botschaft seines Vaters „weitermachen“ ausrief, ballte er vielleicht die Hände zu Fäusten - aber in der Tasche.

Mit der Rückkehr der Asche Marcuses in die Stadt seiner Geburt schloss sich ein Kreis in einem ähnlichen Sinne wie - gemäß der Hegelschen Geschichtsphilosophie - der Geist nach seiner Entäusserung wieder zu sich selbst zurückkehrt. Mir fiel nachträglich ein, bei welcher Gelegenheit ich diese Metapher im Zusammenhang mit Marcuse zum ersten Mal gehört hatte. Das war in einem Gespräch mit Habermas, in dem er von seinem letzten Kontakt mit Herbert erzählte. Marcuse konnte schon nicht mehr sprechen, aber er ver- 
suchte verzweifelt, sich mit einer Geste verständlich zu machen. Die Geste bestand in einer beständig wiederholten kreisförmigen Bewegung seiner Hand. Habermas deutete die Geste als Anspielung auf Hegels Bewusstseinsphilosophie und als Hinweis auf den Geist, der nach seiner Entäußerung wieder zu sich selbst zurückfindet. 